Evidências sorológicas de EHV-1 / EHV-4 em cavalos de vaquejada no estado do Ceará, Brasil

Marcio Gomes de Alencar-Araripe ${ }^{1 *}$; Débora Castelo-Branco de Souza Collares Maia ${ }^{2}$; Cláudio Cabral Campelo ${ }^{1}$; Abelardo Silva Júnior ${ }^{3}$ Michelle Costa e Silva ${ }^{4}$; Aline Viana Dias $^{4}$; Christiane Myrta de Oliveira Medeiros ${ }^{4}$; Diana Célia Sousa Nunes-Pinheiro ${ }^{1}$

Resumo - Vaquejada é um esporte eqüestre popular no nordeste brasileiro, que promove encontros frequentes, onde há uma grande concentração de animais, propiciando a exposição à patógenos. $\mathrm{Na}$ literatura, não existem relatos da presença dos herpesvírus equídeo EHV-1/EHV-4 no Ceará. Objetivou-se determinar o título de anticorpos anti-herpesvírus equídeo (EHV-1/EHV-4) de animais não vacinados no estado do Ceará. Foram utilizados 68 equinos de vaquejada clinicamente saudáveis. Amostras de sangue foram coletadas para avaliações hematológica, bioquímica e sorológica. Os títulos de anticorpos anti-EHV foram determinados através da técnica de soroneutralização. Dos 68 animais avaliados, 28 (41,2\%) foram soropositivos para EHV-1 e/ou EHV-4, com título médio geométrico de 4,76, enquanto que $40(58,8 \%)$ foram negativos para o teste. Não foram encontradas alterações significativas nos parâmetros hematológicos e bioquímicos em animais soropositivos e soronegativos. A idade média dos equinos foi de sete anos e foram observadas leve correlação e leve influência sobre os títulos de anticorpos anti-EHV-1/EHV-4. Este é o primeiro relato de herpesvirus equídeo circulante no Ceará. Outros estudos devem ser realizados para conhecimento e orientação sobre a manutenção da saúde em animais praticantes de vaquejada.

Palavras-chave: Equinos, vaquejada, herpesvírus equídeo, soroneutralização.

\title{
Serological evidences of EHV-1 / EHV-4 in vaquejada horses from Ceará state, Brazil
}

Abstract: Vaquejada is a popular equestrian sport in Northeastern Brazil, which promotes frequent tournaments, where many animals are brought together, leading to 
exposure to pathogens. In the literature, there are no reports of the presence of equid herpesvirus (EHV-1/EHAV-4) in the State of Ceará. This study aimed at determining antiequid herpesvirus (EHV-1/EHV-4) antibody titer of non-vaccinated horses from the state of Ceará. Sixty-eight clinically healthy vaquejada horses were evaluated. Blood samples were collected for hematological, biochemical and serological evaluation. Anti-EHV-1 / EHV-4 antibody titers were determined through serum neutralization technique. Out of the 68 assessed animals, $28(41.2 \%)$ were seropositive for EHV-1 and/or EHV-4, with a mean geometric titer of 4,76, while the remaining 40 (58.8\%) animals were negative for the assay. No significant alterations in the hematological and biochemical parameters were found among seropositive and seronegative animals. The average age of the tested animals was 7 years. A mild positive correlation and a mild influence was observed between age and antibody titer. This is the first report of circulating equid herpesvirus in Ceará. Further studies must be performed to obtain knowledge on promoting the welfare of horses involved in the practice of vaquejada.

Keywords: Equines, vaquejada, herpesvirus, serum neutralization

\footnotetext{
${ }^{1}$ Programa de Pós-graduação em Ciências Veterinárias, Faculdade de Veterinária, Universidade Estadual do Ceará, Av. Paranjana, 1700, Campus do Itaperi. CEP: 60.740-002, Fortaleza-CE, Brasil. * E-mail: marcio.araripe@yahoo.com.br

${ }^{2}$ Programa de Pós-graduação em Microbiologia Médica, Faculdade de Medicina, Universidade Federal do Ceará, Rua Coronel Nunes de Melo, s/n, Rodolfo Teófilo. CEP: 60430-270, Fortaleza-CE, Brasil.

${ }^{3}$ Laboratório de Infectologia Molecular Animal, Instituto de Biotecnologia Aplicada (Bioagro), Laboratório de Virologia Animal, Departamento de Veterinária da Universidade Federal de Viçosa, Av. Ph Rolfs S/N, Viçosa-MG, CEP: 36570-000, Brasil.

${ }^{4}$ LAFORVET - Centro de Medicina Laboratorial Veterinária, Rua Joaquim Torres, 941, Joaquim Távora. CEP: 60135-130, Fortaleza-CE, Brasil.

Autor para correspondência. E. Mail: * marcio.araripe@yahoo.com.br

Recebido em 10/03/2014. Aceito em 14/05/2014
}

\section{Introdução}

As viroses possuem elevada importância sanitária na equideocultura 
mundial, destacando-se as infecções herpéticas (DIEL et al., 2006). Os herpesvírus equideos (EHV) são vírus DNA envelopados pertencentes à família Herpesviridae, $\quad$ subfamília Alphaherpesvirinae (ATASEVEN et al., 2010). EHVs estão filogeneticamente relacionados ao gênero Varicellovirus (ZELL et al., 2012). EHV 1 e 4 infectam as células do hospedeiro por intermédio de uma glicoproteína de membrana independente das integrinas (AZAB \& OSTERRIEDER, 2012). EHV-1 pode causar principalmente aborto, doença neonatal, doença respiratória e doença neurológica, podendo levar o animal a óbito, enquanto que o EHV-4 pode causar doença respiratória e aborto. EHV tem como características manter a infecção de forma latente e possuir como principal fonte de infecção as secreções nasais (HENNINGER et al., 2007).

No Brasil, o primeiro isolamento do EHV foi descrito em 1966 (NILSON \& CORRÊA, 1966). A ocorrência de abortos causados pelo EHV-1 foi notificada em Minas Gerais (CARVALHO et al., 1991), São Paulo (NILSON \& CORRÊA, 1966) e evidências sorológicas de EHV-1 foram relatados no Rio Grande do Sul (VARGAS \& WEIBLEN, 1991) e no Pará (HEINEMANN et al., 2002; PENA et al., 2006). No período de janeiro de 2000 a junho de 2011, estudo realizado no Rio Grande do Sul avaliando 72 casos de abortos em equinos relatou que $3(4,2 \%)$ casos estavam associados à infecção por EHV-1 confirmados por imunohistoquímica (MARCOLONGO-PEREIRA et al., 2012). Na França, em estudo retrospectivo no período de 1986 a 2009 com 1822 casos de aborto em equinos, foi relatado que $14,5 \%$ dos abortos estavam associados à infecção por EHV-1 (LAUGIER et al., 2011).

Os equinos existentes na Região Metropolitana de Fortaleza são, em sua maioria, utilizados para a prática de esportes. Dentre esses esportes, destaca-se a vaquejada, por sua popularidade e pelo 
grande número de praticantes em todo o nordeste brasileiro, sendo comum o deslocamento interestadual de animais. As vaquejadas são frequentes e muitos animais participam semanalmente dessas competições. Nos parques de vaquejada são observadas alta concentração de animais e baixo controle sanitário que podem levar a uma intensa exposição dos animais a patógenos.

$\mathrm{Na}$ tentativa de encontrar evidências da circulação do EHV, objetivou-se determinar o título de anticorpos contra o herpesvírus equídeo (EHV-1/EHV-4) de animais de vaquejada não vacinados na região metropolitana de Fortaleza, Ceará.

\section{Material e Métodos}

Foram utilizados 68 equinos (Equus caballus), machos, com idade entre 3 e 15 anos, de diversas raças, provenientes de propriedades particulares localizadas na região metropolitana da cidade de Fortaleza, Ceará, Brasil, sem histórico de vacinação para EHV. Fortaleza situa-se numa planície litorânea, logo abaixo da linha do Equador, com latitude sul de $3^{\circ} 43^{\prime} 02^{\prime \prime}$ e $38^{\circ} 32^{\prime} 35^{\prime \prime}$ de longitude oeste e

a $16 \mathrm{~m}$ de altitude. Segundo o Instituto Brasileiro de Geografia e Estatística (IBGE) temperatura média anual oscila entre 26 e $28^{\circ} \mathrm{C}$, e a umidade relativa do ar situa-se em torno de $82 \%$ e pluviosidade média de $1.338 \mathrm{~mm}$ anuais.

Os equinos foram avaliados, individualmente, quanto às condições clínicas gerais, à higiene do local onde vivem, à alimentação e ao fornecimento de sal mineral. As informações obtidas foram armazenadas em fichas de avaliação individual. Não foram encontradas alterações dignas de nota.

Foram colhidas amostras de sangue dos 68 equinos através da venopunção da jugular, com agulhas $21 \mathrm{G}$ apropriadas para tubos com vácuo, distribuídas em frascos com EDTA e sem anticoagulante. Amostras de soro foram obtidas após centrifugação por dez minutos a $4.000 \mathrm{rpm}$, e estocadas a $-20^{\circ} \mathrm{C}$ até o 
momento dos exames laboratoriais

(AGUIAR et al., 2008; LARA et al., 2003; PENA et al., 2006).

Nas amostras de sangue em EDTA foram realizadas a contagem de leucócitos totais e dosagem de hemoglobina em aparelho de automação hematológica e nos soros foram determinados os teores de proteínas totais (PT) utilizando-se kits comerciais com metodologia colorimétrica, seguindo as orientações do fabricante e a titulação de anticorpos anti-EHV-1 e/ou anti-EHV-4 através da técnica de soroneutralização (SN), segundo HOUSE \& BAKER (1971, adaptado).

Previamente, as amostras de soro foram inativadas em banho-maria a $56^{\circ} \mathrm{C}$ por $30 \mathrm{~min}$. SN foi realizada com a utilização de células VERO (células de rim de macaco verde africano), em cultura estéril com meio essencial mínimo - MEM (GIBCO), adicionado $5 \%$ de soro fetal bovino. As culturas foram mantidas e incubadas em estufa a $37^{\circ} \mathrm{C}$ e $5 \%$ de $\mathrm{CO}_{2}$ e replicadas a cada 72 horas, usando tripsina a $37^{\circ} \mathrm{C}$, para deslocar a monocamada. Uma alíquota de $200 \mu$ l DICC50/50 EHV-1 (Laboratório de Virologia do Departamento de Medicina Veterinária Preventiva da Universidade Federal de Santa Maria) foi adicionada, em diluição seriada do soro (fator de diluição 2), variando de 1:2 a 1:128. Após a incubação da mistura soro-vírus por $90 \mathrm{~min}$, a $37^{\circ} \mathrm{C}$, em câmara de $\mathrm{CO}_{2}, 50 \mu \mathrm{L}$ da suspensão de células VERO, na concentração de 300.000 células/mL foram adicionados. A leitura dos resultados foi realizada após 72 h de incubação, por meio do monitoramento do efeito citopático (ECP) nos cultivos celulares. $\mathrm{O}$ título neutralizante foi considerado de acordo com a maior diluição capaz de prevenir a produção de ECP (DIEL et al., 2006). Os animais positivos foram incluídos no grupo soropositivos e os animais não reagentes foram incluídos no grupo soronegativos.

Os resultados foram expressos em percentagem de animais soropositivos e soronegativos e os dados dos exames 
hematológicos e bioquímicos em media \pm desvio padrão. Foi realizada uma análise de correlação entre o título de anticorpos e a idade dos animais avaliados.

Este projeto foi desenvolvido após aprovação pelo Comitê de Ética para Uso de Animais (CEUA) da Universidade Estadual do Ceará com o protocolo $\mathrm{n}^{\circ}$ 09232603-0/70, tendo respeitado e seguido todos os princípios éticos recomendados quanto à utilização de animais em experimentos.

\section{Resultados}

O presente estudo pesquisou pela primeira vez a presença de anticorpos contra EHV-1 e/ou EHV-4 em equídeos criados no Estado do Ceará. Os dados do teste de soroneutralização estão dispostos na Tabela 1. Dos 68 soros avaliados, 28
$(41,2 \%)$ neutralizaram a ação do EHV-1 in vitro, o título médio geométrico foi de 4,76, enquanto que $40(58,8 \%)$ foram negativos para o teste. Houve leve correlação e uma leve influência entre a idade e o título de anticorpos anti-EHV-1 (Figura 1).

A avaliação clínica dos animais foi complementada através da determinação dos parâmetros hematológicos e bioquímicos séricos como expressos na Tabela 2. Os valores médios de leucócitos totais, hemoglobina, plaquetas e proteínas totais para os grupos de animais estudados encontravam-se dentro dos valores de referência para a espécie. Quando os animais foram agrupados em soronegativos e soropositivos também não foram observadas alterações significativas entre os parâmetros avaliados. 
Tabela 1: Soroneutralização para EHV-1 em equinos de vaquejada da Região Metropolitana de Fortaleza, Ceará.

\begin{tabular}{lll}
\hline Título & $\mathrm{N}^{\circ}$ de animais & Porcentagem \\
\hline 0 & 40 & $58,8 \%$ \\
2 & 8 & $11,76 \%$ \\
4 & 9 & $13,24 \%$ \\
8 & 7 & $10,29 \%$ \\
16 & 4 & $5,88 \%$ \\
32 & 0 & $0 \%$ \\
64 & 0 & $0 \%$ \\
128 & 0 & $0 \%$ \\
\hline Total de positivos & 28 & $41,2 \%$ \\
\hline
\end{tabular}

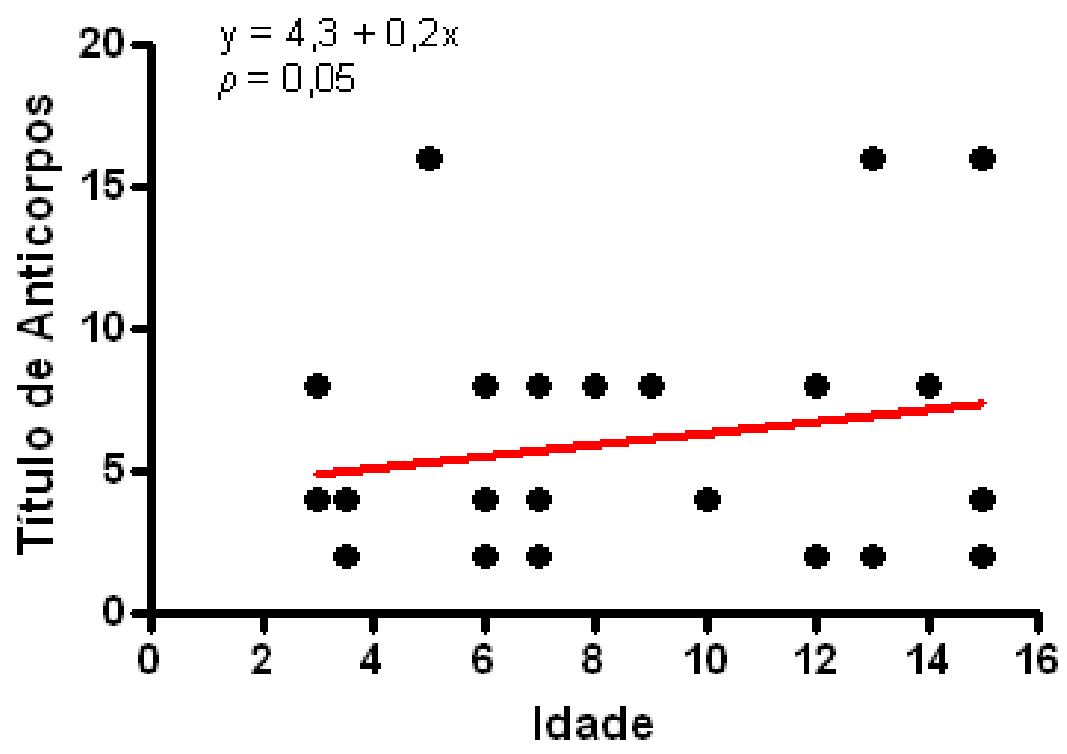

Figura 1: Influência da idade sobre o título de anticorpos anti-EHV-1 em equinos de vaquejada da Região Metropolitana de Fortaleza, Ceará. 
Tabela 2: Parâmetros hematológicos e bioquímicos em equinos de vaquejada da Região Metropolitana de Fortaleza, Ceará.

\begin{tabular}{lcccc}
\hline Parâmetros & Valores de & Total & Soronegativos & Soropositivos \\
Referência & Min - Máx & Min - Máx & Min - Máx \\
& Média \pm D.P. & Média \pm D.P. & Média \pm D.P. \\
& $(\mathrm{n}=68)$ & $(\mathrm{n}=40)$ & $(\mathrm{n}=28)$
\end{tabular}

\section{Hematológico *}

Leucócitos $\left(\mathrm{x} 10^{3} / \mathrm{mm}^{3}\right) \quad 5,50-12,50 \quad 3,70-11,70 \quad 3,70-11,60 \quad 3,90-11,70$

$$
6,25 \pm 1,70 \quad 6,10 \pm 1,67 \quad 6,30 \pm 1,75
$$

Hemoglobina $(\mathrm{g} / \mathrm{dL}) \quad 11-19 \quad 6,10-15,60 \quad 6,10-15,60 \quad 7,60-15,40$

$$
11,75 \pm 1,84 \quad 11,30 \pm 1,74 \quad 12,40 \pm 1,96
$$

Plaquetas $\left(x 10^{3} / \mathrm{mm}^{3}\right) \quad 100-350 \quad 116-423 \quad 138-364 \quad 116-423$

$$
270 \pm 57,10 \quad 281 \pm 51,83 \quad 248 \pm 63,04
$$

\section{Bioquímico **}
Proteínas Totais $(\mathrm{g} / \mathrm{dL}) \quad 5,70-7,00$
$5,80-7,40$
$6,75 \pm 0,36$
$5,80-7,40$
$6,20-7,40$
$6,75 \pm 0,39$
$6,75 \pm 0,31$

* JAIN, 1993.

** KANEKO, 1997.

\section{Discussão}

Os animais utilizados nesse estudo apresentaram-se sem sinais clínicos dignos de nota e sem alterações laboratoriais, apresentando-se clinicamente hígidos. Nossos dados não revelam diferença 
significativa entre os dados hematológicos

e bioquímicos de animais soropositivos e soronegativos. A idade média dos equinos adultos e machos em estudo foi de 7 anos. Dos animais avaliados $41,2 \%$ foram positivos para herpesvirus com título médio geométrico de 7,29 para EHV-1 e/ou EHV-4. Nossos dados demonstraram leve correlação e uma leve influência entre a idade e título dos anticorpos.

Tem sido relatado que a idade é um fator determinante para o aumento da prevalência da infecção por EHV, provavelmente relacionada a uma maior probabilidade de o animal entrar em contato com o vírus (LARA et al., 2010). As fontes mais comuns de infecção por EHV-1 e 4 são animais adultos, porque eles podem excretar o vírus nas secreções nasais após a reativação de infecções latentes (HENNINGER et al., 2007). Levando-se em conta que o macho é utilizado para o melhoramento genético do rebanho, entrando em contato com diversas fêmeas, ele sendo contaminado, torna-se um possível propagador do vírus, disseminando-o, trazendo sérias repercussões sanitárias.

Segundo informações dos proprietários nenhum animal foi vacinado contra EHV. Nossos resultados evidenciam a existência do vírus em animais da região metropolitana de Fortaleza, Ceará. Ressaltando que as espécies EHV-1 e 4 são antigenicamente relacionadas, considera-se que o teste de diagnóstico utilizado, por meio da soroneutralização, não diferencia os anticorpos detectados quanto ao tipo viral. Esse fato deve ser levado em conta, devido a possíveis infecções pelo EHV-4 na população estudada, visto que o EHV-4 já foi descrito no Brasil, em equinos do Estado de São Paulo (MORI et al., 2008). Nesse aspecto, as amostras de soro reagentes para EHV-1 identificados neste estudo poderiam ser, alternativamente, reativas a EHV-4.

A provável explicação para a maior frequência de amostras com baixo título de anticorpos (2 e 4) pode ser atribuída ao 
mecanismo de latência desenvolvido por esse agente que permite a persistência do vírus, mesmo em um rebanho fechado. Animais portadores podem, eventualmente, eliminar o vírus. A elevada percentagem de animais com baixo título de anticorpos pode indicar a presença de anticorpos residuais, produtos de infecção primária antiga ou reativação viral (KYDD et al., 2006).

Em nosso trabalho, 41,2\% dos soros avaliados foram EHV-1 positivos. Em São Paulo, foram encontrados 17,6\% das amostras positivas (MONDOLO et al., 1989 ) e em Minas Gerais 18,7\% dos cavalos eram soropositivos (LARA et al., 2010). Em um estudo sorológico realizado em rebanhos com problemas reprodutivos no Rio Grande do Sul, foram detectados $84,7 \%$ de positividade entre as 348 amostras testadas para o EHV-1, utilizando a prova de soroneutralização (VARGAS \& WEIBLEN, 1991).

Em 1993, foi realizado um estudo pela EMBRAPA/CPAP, com a cooperação do Animal Health Institute da Inglaterra, com 50 equinos, incluindo animais que apresentavam sintomatologia respiratória, o qual demonstrou $36 \%$ dos animais positivos para o EHV-1 e 58\% dos animais positivos para o EHV-4 (SORIANO et al., 1997). A prevalência de $17,71 \%$ de equinos soropositivos observada por HEINEMANN et al. (2002) aproxima-se dos dados obtidos por DIAS (2000), que observou $21,70 \%$ e $13,18 \%$ de animais soropositivos na Ilha de Marajó e no resto do Estado do Pará, respectivamente. No estado do Rio Grande do Sul, foram analisados 1.506 soros dos quais $4,5 \%$ foram positivos (DIEL et al., 2006). No Paraná, um estudo realizado nas cidades de Curitiba e de São José dos Pinhais, demonstrou que $4,1 \%$ dos cavalos foram positivos para EHV-1 (LARA et al., 2006). $\mathrm{O}$ primeiro isolamento do $\mathrm{EHV}-1$ neuropatogenico no Brasil foi realizado a partir de uma égua com mieloncefalopatia herpética que foi a óbito (LARA et al., 2008). No mesmo ano, foi detectado DNA 
viral no sistema nervoso central, por meio da reação em cadeia da polimerase (PCR), de um garanhão que morreu com menos de 12 horas após o início dos sinais neurológicos (COSTA et al., 2008). Uma estirpe mutante neuropatogênica (G2254) do EHV-1 foi isolada a partir de uma mieloencefalopatia herpética em uma égua oriunda de Botucatu, São Paulo (MORI et al., 2010).

Os sinais neurológicos constituem o extremo das alterações observadas na doença por EHV-1, sendo, portanto, observados mais abortos que manifestações neurológicas. Fatores individuais como idade, imunidade, fatores hormonais e estresse do hospedeiro, assim como a reativação das cepas latentes de EHV-1 e a ocorrência de infecções duplas podem ser determinantes para 0 desenvolvimento de sinais neurológicos. Adicionalmente, foram observadas mudanças de aminoácidos na posição 752 influenciam a ocorrência de sinais neurológicos (NUGENT et al., 2006)
Estudos realizados com equinos utilizados em vaquejadas relatam a ocorrência de alterações físicas, bioquímicas e hematológicas em decorrência do estresse associado ao exercício físico, devido à falta de treinamento adequado e às condições ambientais inóspitas dos parques de vaquejada (LOPES et al., 2009). A concentração de equinos de diversas procedências mantendo contato próximo pode expor os indivíduos a uma série de patógenos.

O tipo de atividade desenvolvida pelas diferentes espécies e o frequente deslocamento podem explicar a hipótese de os equinos serem mais suscetíveis às infecções virais (ATASEVEN et al., 2009), além do contato com outros animais que aumenta o risco de infecção (DIEL et al., 2006). O deslocamento desses animais soropositivos para EHV-1 e/ou EHV-4 pode contribuir para a disseminação do vírus. 


\section{Conclusões}

Os equinos utilizados em vaquejada apresentaram evidências sorológicas da presença do EHV-1 e/ou EHV-4. Este é o primeiro relato de herpesvirus equídeo circulante na Região Metropolitana de Fortaleza. Outros estudos devem ser realizados no estado do Ceará para conhecimento e orientação sobre a manutenção da saúde em animais praticantes do esporte de vaquejada. Considerando a importância da equideocultura, é essencial alocar recursos para promover políticas de saúde para combater este vírus, pois o estudo analítico da epidemiologia favorece a implantação de medidas adequadas para o controle da disseminação do EHV-1 e 4.

\section{Agradecimentos}

7.

Agradecemos ao Laboratório de Virologia Animal da Universidade Federal de Viçosa (UFV) pela parceria e excelência em virologia. Esse estudo foi parcialmente financiado pela Coordenação de Aperfeiçoamento de Pessoal de Nível Superior (CAPES).

\section{Referências Bibliográficas}

AGUIAR, D.M.; CAVALCANTE, G.T.; LARA, M.C.C.S.H. et al. Prevalência de anticorpos contra agentes virais e bacterianos em equídeo s do município de Monte Negro, Rondônia, amazônia ocidental brasileira. Braz. J. Vet. Res. Anim. Sci., v.45, n.4, p.269-276, 2008.

ATASEVEN, V.S.; BILGE-DAĞALP, S.; BAŞARAN, Z.; KESKIN, S. Seroepidemiological studies of equine herpesviruses 1 (EHV-1) and 4 (EHV-4) infections in working horses from the eastern Turkey, Ankara. Kafkas Univ. Vet. Fak. Derg., v.57, p.39-42, 2010.

ATASEVEN, V.S.; DAGALP, S.B.; GUZEL, M. et al. Prevalence of equine herpesvirus-1 and equine herpesvirus-4 infections in equidae species in Turkey as determined by ELISA and multiplex nested PCR. Res. Vet. Sci., v.86, p.339-344, 2009. AZAB, W.; OSTERRIEDER, N. Glycoproteins D of Equine Herpesvirus Type 1 (EHV-1) and EHV-4 Determine Cellular Tropism Independently of 
Integrins. J. Virol., v.86, n.4, p.2031-2044, 2012.

CARVALHO, F.S.R.; COELHO, H. E.; BEDAQUE, M. Aborto equino por herpesvirus equi 1. Rev. Cent. Ciênc. Bioméd. Univ. Fed. Uberlândia., v.7, p.4547, 1991.

COSTA, E.A.; LIMA, G.B.L.; CASTRO, R.T. et al. Meningoencephalitis in a horse associated with equine herpesvirus 1. Arq. Bras. Med. Vet. Zootec., v.60, n.6, p.15801583,2008

DIAS, H.L.T. Soroepidemiologia de cinco enfermidades infecciosas em equinos criados no estado do Pará. 2000. 147f. Belém, PA. Tese (Doutorado em Medicina Veterinária Preventiva) - Programa de Doutorado em Ciências Biológicas, Universidade Federal do Pará.

DIEL, D.G.; ALMEIDA, S.R.; WEIBLEN, R. et al. Prevalência de anticorpos contra os vírus da influenza, da arterite viral e herpesvirus em equinos do estado do Rio Grande do Sul, Brasil. Ciênc. Rural., v.36, n.5, p.1467-1673, 2006.
HEINEMANN, M.B.; CORTEZ, A.; SOUZA, M.C.C. et al. Soroprevalência da anemia infecciosa equina, da arterite viral dos equinos e do aborto viral equino no município de Uruará, PA, Brasil. Braz. J. Vet. Res. Anim. Sci., v.39, n.1, p.50-53, 2002.

HENNINGER, R.W.; REED, S.M.; SAVILLE, W.J. et al. Outbreak of neurologic disease caused by equine herpesvirus-1 at a university equestrian center. J. Vet. Intern. Med., v.21, p.157165, 2007.

JAIN, N.C. Comparative hematology of common domestic animals. In: JAIN, N.C. (ed) Essentials of veterinary hematology. 1st ed. Philadelphia: LEA \& FEBIGER, 1993. p.19-53.

KANEKO, J.J.; HARVEY, J.W.; BRUSS, M.L. Clinical biochemistry of domestic animals. 5th ed. New York: ACADEMIC PRESS, 1997. p.885-906.

KYDD， J.H.; TOWNSEND， H.G.; HANNANT, D. The equine immune response to equine herpesvirus-1: the virus 
and its vaccines. Vet. Immunol. Immunop., v.111, p.15-30, 2006.

LARA, M.C.C.S.H.; CUNHA, E.M.S.; NASSAR, A.F.C. et al. Ocorrência do herpesvírus equídeo 1 (HVE-1) em cavalos criados no estado de São Paulo, Brasil. Ars Veterinaria., v.19, n.3, p.254-259, 2003.

LARA， M.C.C.S.H.; FURMAN， K.E.; BARROS FILHO, I.R. et al. Detection of antibodies against equine viral arteritis virus (EVAV) and equine herpesvirus type $1(\mathrm{EHV}-1)$ in cart horses from Curitiba and surroundings, southern Brazil. Arch. Vet. Sci., v.11, p.11-14, 2006.

LARA, M.C.C.S.H.; CUNHA, E.M.S.; VILLALOBOS, E.M.C. et al. First isolation of equine herpesvirus type 1 from a horse with neurological disease in Brazil. Arq. Inst. Biol., São Paulo, v.75, n.2,p.221224, 2008.

LARA, M.C.C.S.H.; TORELLI, C.S.; CUNHA, E.M.S. et al. Inquérito sorológico da infecção por herpesvírus equino no Estado de Minas Gerais. Braz. J.
Vet. Res. Anim. Sci., São Paulo, v.47, n.5, p.352-356, 2010.

LAUGIER, C.; FOUCHER, N.; SEVIN, C. et al. A 24-year retrospective study of equine abortion in Normandy (France). $J$. Equine Vet. Sci., v.31, p.116-123, 2011.

LOPES, K.R.F.; BATISTA, J.S.; DIAS, R.V.C.; SOTO-BLANCO, B. Influência das competições de vaquejada sobre os parâmetros indicadores de estresse em equinos. Ci. Anim. Bras., v.10, n.2, p.538543, 2009.

MARCOLONGO-PEREIRA, C.; ADRIEN, M.L.; LADEIRA, S.R.L. et al. Abortos em equinos na região Sul do Rio Grande do Sul: estudo de 72 casos. Pesqui. Vet. Bras., v.32, n.1, p.22-26, 2012.

MONDOLO, J.R.; PETZOLDT, K.; GOTTS-CHALK, A.F. et al. Investigação sorológica do herpesvirus equi-1 em equinos pelo teste de fixação do complemento, considerações sobre seu uso na saúde do haras. A Hora Vet., v.8, p.2527, 1989. 
MORI, E.; CASTRO, A.M.M.G.; LARA, M.C.C.S.H. et al. Occurrence of equid herpesvirus (EHV-1) and (EHV-4) infections in asymptomatic equid population in São Paulo State, Brazil. In: Anais... Virus Rev. Res., Minas Gerais, Brasil. 2008. 101p.

MORI, E.; BORGES, A.S.; DELFIOL, D.J.Z. et al. FIRST DETECTION OF THE EQUID HERPESVIRUS $\quad 1$ NEUROPATHOGENIC VARIANT IN BRAZIL. Ver. Sci. Tech., v.30, p.1-6, 2010.

NILSON, M.R.; CORRÊA, W.M. Isolamento do vírus do aborto equino no estado de São Paulo. Arq. Inst. Biol., v.33, p.23-35, 1966.

NUGENT, J.; BIRCH-MACHIN， I.; SMITH, K.C. et al. Analysis of equid herpesvirus 1 strain variation reveals a point mutation of the DNA polymerase strongly associated with neuropathogenic versus nonneuropathogenic disease outbreaks. J. Virol., v.80, p.4047-4060, 2006.
PENA, L.J.; PENA, D.A.; BARRIOS, P.R. et al. Levantamento soro-epidemiológico da infecção pelo vírus da anemia infecciosa equina, da influenza equina-2 e do herpesvírus equino-1 em rebanhos do sul do estado do Pará, Brasil. Braz. J. Vet. Res. Anim. Sci., v.43, n.4, p.537-542, 2006. SORIANO, B.M.A.; OLIVEIRA， H.D.; CATTO, J.B. et al. Plano de utilização da fazenda Nhumirim Documento 21. In: Centro de Pesquisa Agropecuária do Pantanal. Corumbá:EMBRAPA-CPAP, 1997. p.1-72.

VARGAS, A. C.; WEIBLEN, R. Antibody prevalence against equine herpesvirus type 1 (EHV-1) in some counties of Rio Grande do Sul state. A Hora Vet., v.10, n.59, p.5-8, 1991.

ZELL, R.; TAUDIEN, S.; PFAFF, F. et al. Sequencing of 21 varicella-zoster virus genomes reveals two novel genotypes and evidence of recombination. J. Virol., v.86, n.3, p.1608-1622, 2012. 